\title{
Oral Anticoagulation in the Elderly and Frail
}

\author{
Rupert M. Bauersachs ${ }^{1,2}$ Joerg Herold ${ }^{1}$ \\ ${ }^{1}$ Department of Vascular Medicine, Klinikum Darmstadt GmbH,
Darmstadt, Germany
${ }^{2}$ Center for Thrombosis and Hemostasis, University Medical Center,
Mainz, Germany
}

Address for correspondence Rupert M. Bauersachs, Department of Vascular Medicine, Klinikum Darmstadt GmbH, Grafenstraße 9, 64283 Darmstadt, Germany (e-mail: bauersachs@em.uni-frankfurt.de).
Hämostaseologie 2020;40:74-83.

\begin{abstract}
Keywords

- anticoagulation

- elderly

- frail

- atrial fibrillation

- venous thromboembolism

The proportion of elderly patients will increase substantially over the next decades, and both atrial fibrillation (AF) and venous thromboembolism (VTE) are more common in the elderly. Age is a risk factor not only for stroke and thromboembolism but also for bleeding, particularly in frail patients, in whom numerous pathophysiological changes occur that alter drug kinetics and toxicity of standard doses of oral anticoagulants (OACs). AF trials showed that the relative benefits of direct OACs (DOACs) also applied to elderly patients, and due to their higher risk this translates into a higher absolute risk reduction compared with vitamin $\mathrm{K}$ antagonists, suggesting that DOACs are the better choice. All DOACs-at varying extent-are eliminated via the kidney and it is crucial to evaluate renal function at initiation and during follow-up, especially for dabigatran. The fear of falls is a common reason against OAC. However, there is still a benefit with OAC, particularly with DOACs given the lower risk of intracranial hemorrhage. Polypharmacy represents a common challenge, nevertheless DOACs and warfarin were classified as beneficial. Nonetheless, attempts should be undertaken to reduce comedication, and drug-drug interactions should be assessed. Coadministration of platelet inhibitors increases bleeding risk and should be avoided. In conclusion, elderly and frail patients requiring anticoagulation for AF or VTE are at higher risk of adverse outcomes, but also have a higher absolute benefit from OAC. Important practical aspects to improve efficacy and safety in this challenging population are summarized in this overview.
\end{abstract}

\section{Epidemiology}

\section{Elderly Patients and Venous Thromboembolism}

In Germany the percentage of persons above 60 years will increase by 39\% from 2013 to 2050, when more than onethird of the population will be above 60 years, ${ }^{1}$ and the proportion above 67 years will increase by $33 \%$ from 2020 to 2060 , when more than 21 million persons above that age will live in Germany. ${ }^{2}$ While the overall incidence of venous thromboembolism (VTE) is approximately 1 to 2 per 1,000 per year, it increases to $1 \%$ per year in the elderly. ${ }^{3}$ Thus, the great majority of patients treated for VTE are elderly: already 20 years ago more than $70 \%$ of VTE patients were above 60 years, ${ }^{4}$ and it is foreseeable that this will increase in the

received

September 11, 2019

accepted after revision

December 10, 2019

future. In addition, the case fatality rate of VTE is higher in the elderly, especially in those with cancer, which is more prevalent at higher age. Unfortunately, the risk of major bleeding during anticoagulation is also age-dependent, contributing to the vulnerability of this patient group. ${ }^{3}$ In view of these challenges, it is remarkable that this age group is underrepresented in most of the large VTE trials, ${ }^{5}$ which is an additional hurdle for the translation of evidence-based data into clinical practice.

\section{Elderly Patients and Atrial Fibrillation}

The increase of the elderly population has a similar bearing on the number of patients suffering from atrial fibrillation (AF) (c) 2020 Georg Thieme Verlag KG
Stuttgart · New York
DOI https://doi.org/ 10.1055/s-0040-1701476. ISSN 0720-9355. 
and the subsequent risk of major stroke. The ATRIA study, ${ }^{6}$ based on a total of 17,974 patients with AF, showed that the prevalence of $\mathrm{AF}$ increases from $0.1 \%$ in adults younger than 55 years to $9.0 \%$ in persons of 80 years or older. It was projected that the prevalence of AF will increase in the United States to more than 5.6 million by the year 2050 , with more than $50 \%$ of affected individuals being 80 years or older. The importance of age as a serious risk factor for stroke in $\mathrm{AF}$ is reflected in the $\mathrm{CHA}_{2} \mathrm{DS}_{2}$-VASc Score, ${ }^{7}$ where age is counted double.

\section{Frailty}

Frailty is a geriatric syndrome resulting from age-related cumulative declines across multiple of physiologic systems, with impaired homeostatic reserve and a reduced capacity of the organism to withstand stress, thus increasing vulnerability to adverse health outcomes including falls, hospitalization, institutionalization, and mortality. ${ }^{8,9}$ However, also other losses of human functioning occur, i.e., psychological or social. The actual state of the frail elderly person is dynamic and it can be positioned on a continuum between nonfrail and frail. ${ }^{10} \mathrm{Not}$ unexpectedly therefore, different and varying definitions of frailty are being utilized. Most commonly, a phenotypic definition of frailty is being used, based on readily identifiable physical aspects ${ }^{11}$; three or more of the following characteristics support a frailty diagnosis: unintended weight loss, exhaustion, weakness, slow gait speed, and low physical activity. ${ }^{8}$ Recent trials on antithrombotic treatment have defined fragile patients as including, but not limited to, elderly patients (e.g., above 75 years), patients with renal impairment (glomerular filtration rate [GFR] below $50 \mathrm{~mL} / \mathrm{min}$ ), and those with low body weight (below $50 \mathrm{~kg}$ ). ${ }^{12}$ Fragility is associated with decreased reserve to challenges due to a general decline in physiologic systems leading to poorer outcomes, complications, and mortality. ${ }^{12-14}$ In a recent systematic review and meta-analysis, approximately $40 \%$ of adults with AF over the age of 80 who are admitted to an acute care hospital are diagnosed as frail. ${ }^{15}$ Clinical studies as well as data from the prospective RIETE registry indicate that VTE treatment in elderly patients and those with renal impairment or low body weight is associated with a higher bleeding risk. ${ }^{16,17}$

\section{Challenges of Anticoagulation in the Elderly and Frail}

\section{Elderly Patients}

Multiple physiological and pathological changes occur in the elderly including changes in body composition, relative increase of body fat due to a loss of lean body mass, and reductions in total body water, which alter drug kinetics ${ }^{18}$ and the distribution volume of anticoagulation drugs, increasing the toxicity of standard doses. ${ }^{19}$ Due to limited dietary vitamin $\mathrm{K}$ intake or reduced absorption of vitamin K, elderly patients have a lower ability to synthesize clotting factors. ${ }^{19}$ For clinical management it is important to be aware that elderly patients show the greatest variability in vitamin $\mathrm{K}$ antagonist (VKA) dose requirements and take longer time to return to a normal international normalized ratio (INR) from either therapeutic or supratherapeutic INR. ${ }^{19}$ The initial and maintenance doses of VKA are usually lower in elderly patients, and the recommended standard warfarin starting dose of $5 \mathrm{mg}$ may be too high for up to $82 \%$ of women and $65 \%$ of men aged over 70 years. ${ }^{19,20}$ Because of the age-related physiological changes, comorbidities, and concomitant medications, the management of VKA in elderly patients is challenging and associated with an increased risk of adverse events. ${ }^{21}$ In addition, older patients more often have problems to attend clinics regularly for INR monitoring and to maintain-often complicated-dosing schedules. Therefore, poor anticoagulation control with the classical VKA treatment is likely, ${ }^{21}$ and there is an increased risk of bleeding in anticoagulated patients above 65 years. ${ }^{19}$ Nonetheless, the risk for fatal PE is greater than the risk of fatal bleeding in elderly patients, emphasizing the need to carefully evaluate the benefit-risk ratio in these patients. ${ }^{16}$

These considerations often lead physicians to not prescribe oral anticoagulant (OAC), which remains underutilized in the elderly, ${ }^{22}$ even though it has been shown in several analyses that elderly patients benefit from VKA, and even more from direct OAC (DOAC) administration. ${ }^{23} \mathrm{~A}$ systematic review and metaregression analysis of 10 studies comparing warfarin with no warfarin and 16 studies comparing warfarin with DOACs was performed in AF patients above 65 years. Warfarin was found to be superior to no antithrombotic therapy [relative risk (RR): 0.59 (95\% confidence interval [CI]: 0.51-0.76)] and aspirin [RR: 0.44 (0.24-0.64)] for stroke/thromboembolism (TE) prevention. Warfarin use was associated with a nonsignificant increase in risk of major bleeding compared with no antithrombotic therapy (RR: 1.26 [0.99-1.52]) or with aspirin (RR: 1.20 [0.91-1.50]), respectively. DOACs were superior to warfarin for stroke/TE prevention (hazard ratio [HR]: 0.81 [0.73-0.89]), and DOACs also were associated with a reduced risk of major bleeding compared with warfarin (HR: 0.87 [0.77-0.97]).

The phase III trials of DOACs in AF included a significant proportion of patients above 75 years, ranging from 31 to $43 \%$ and representing more than 27,000 elderly patients in whom DOAC treatment was analyzed. A meta-analysis showed no interaction for age with respect to both safety and efficacy, ${ }^{24}$ indicating that the RR difference was not different for elderly patients, while the absolute risk reduction for both thrombotic and bleeding events was higher in the elderly with DOACs compared with VKA, translating into a lower number needed to treat compared with younger patients..$^{25}$ The PREFER in AF prospective registry ${ }^{26}$ with 3,825 patients above 75 years showed that the net composite endpoint, including major bleeding and ischemic cardiovascular events, occurred in $6.6 \%$ per year with DOACs (apixaban, dabigatran, and rivaroxaban) and in 9.1\% per year with VKA (odds ratio [OR]: 0.71 [0.51-0.99]), and DOAC therapy was associated with a lower rate of major bleeding compared with VKA use (OR: 0.58 [0.38-0.90]). It was concluded that DOACs are associated with a better net clinical benefit in elderly AF patients, primarily due to lower rates of major bleeding.

In VTE trials also, a reduced risk of major bleeding was found with rivaroxaban in patients above 75 years [HR: 0.26 [0.12-0.56]), $\mathrm{CrCl}$ below $50 \mathrm{~mL} / \mathrm{min}(0.21$ [0.06-0.73]), or frail patients $(0.27[0.13-0.54]){ }^{14,27,28}$ Similarly, major bleeding was reduced with apixaban versus VKA (HR: $0.63[0.51-0.77]){ }^{29}$ 
Also, in the phase III VTE trial with edoxaban, a high efficacy was found in elderly patients. ${ }^{30}$

\section{Renal Impairment}

There is a well-known association between increasing age and deterioration of renal function ${ }^{13}$ ( - Fig. 1). Criteria for categorizing chronic kidney disease (CKD) have been published ${ }^{31-33}$ and they are mainly based on equations to estimate the GFR from serum creatinine ( $\left(\mathrm{GFR}_{\text {creat }}\right)$ rather than relying on the serum creatinine alone. The degree of albuminuria further defines the outcome of CKD.

In $\mathrm{AF}$ there is a double-sided relationship with $\mathrm{CKD}$, as $\mathrm{AF}$ facilitates the progression of CKD, while on the other hand the incidence and prevalence of $\mathrm{AF}$ increases with deteriorating renal function. ${ }^{34}$ In the Chronic Renal Insufficiency Cohort (CRIC), ${ }^{35}$ nearly one in five participants with CKD had evidence of $\mathrm{AF}$, a prevalence similar to patients with end-stage renal disease and two to three times higher than the general population. Patients with impaired renal function and AF or after VTE have a significantly increased risk for stroke or VTE recurrence, respectively. ${ }^{36-40}$ At the same time these patients are at an increased risk for bleeding, ${ }^{39,40}$ with an additional increase while on OAC. ${ }^{41}$

For VTE, renal insufficiency had not been considered a classical risk factor for the occurrence of VTE; however, an analysis of more than 75,000 postoperative patients showed a doubling of the VTE incidence in patients with renal insufficiency. ${ }^{42}$ More than $60 \%$ of all VTE occur in patients over 70 years, and up to $25 \%$ of patients hospitalized for VTE have moderate-to-severe renal impairment. ${ }^{43,44}$

\section{Vitamin K Antagonists}

In patients with impaired renal function treated with VKA, an increased risk for bleeding is well known and this is reflected in several bleeding scores including the HAS-BLED Score ${ }^{45}$ or the HEMORR2HAGES Score. ${ }^{46}$ Due to the increased bleeding with VKA in patients with CKD, an FDA (U.S. Food and Drug Administration) black-box warning was issued for warfarin, and in Germany phenprocoumon is contraindicated in manifest renal insufficiency. Renal impairment alters binding to plasma proteins, volume of distribution, and nonrenal clearance of many drugs, leading either to toxicity or ineffective therapy. ${ }^{47}$ Although warfarin is hepatically cleared, CKD may impact its metabolism due to downregulation of hepatic enzymes. ${ }^{47}$ Thus, patients with CKD require more frequent monitoring to ensure therapeutic anticoagulation with VKAs. ${ }^{48}$ CKD is associated with decreased warfarin maintenance doses and poorer anticoagulation stability. ${ }^{49}$ Warfarin dose adjustments are required twice as often in patients with CKD compared with patients with normal renal function ( 22 vs. $12 \%$ of visits, respectively), and time in therapeutic range (TTR) is significantly lower in these patients (62 vs. $74 \%$ ). ${ }^{34}$ Patients with CKD are four times more likely to be overanticoagulated (INR $>4.0$ ), increasing the possibility of hemorrhage. ${ }^{48,49}$ The incidence of both minor and major bleeding events is significantly increased in patients with severe CKD compared with patients with moderate CKD and those with normal renal function. ${ }^{48}$

\section{Direct Oral Anticoagulants}

All four available DOACs are at least partially eliminated via the kidney, with dabigatran etexilate having the largest extent of

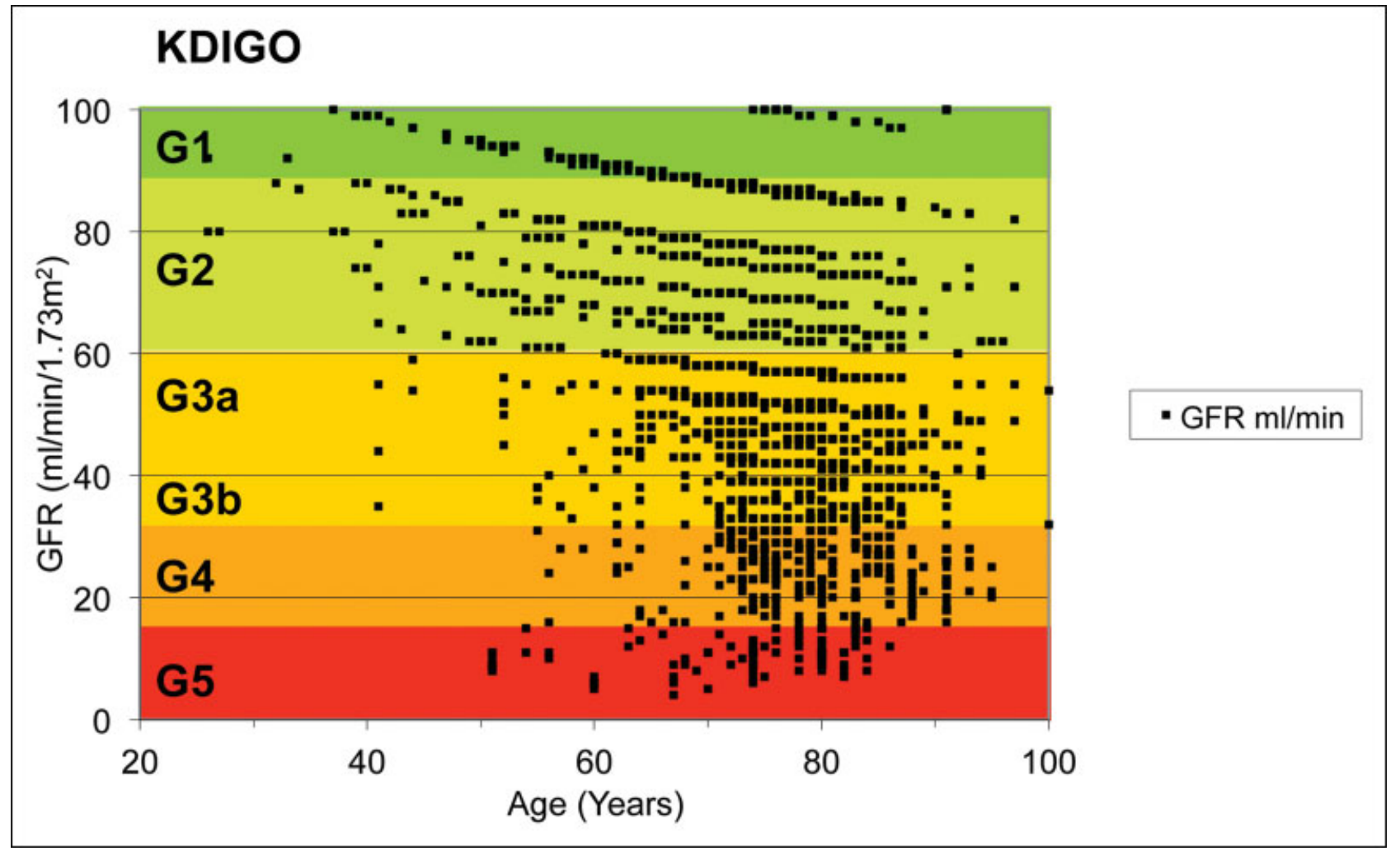

Fig. 1 Correlation between different stages of renal impairment according to the KDIGO (Kidney Disease: Improving Global Outcomes) classification 27,29 and age in 2,150 vascular patients. (Data on file Klinikum Darmstadt $\mathrm{GmbH}$ ). 
renal elimination (80\%), less for edoxaban (50\%), rivaroxaban (33\%), and apixaban (22\%), respectively. ${ }^{13}$ Therefore, it is crucial to evaluate renal function at the initiation of DOAC anticoagulation. As mentioned above, equations to estimate the GFR should be utilized, and the CKD-EPI equation estimating the GFR is recommended by the National Kidney Foundation, because it has been shown to be reliable across the range of CKD stages. In patients on DOACs, renal function needs to be monitored diligently, at least yearly to detect changes in renal function and adapt the dose accordingly. If renal function is impaired (i.e., $\mathrm{CrCl}<60 \mathrm{~mL} / \mathrm{min}$ ), a more frequent evaluation is recommended (e.g., by dividing $\mathrm{CrCl}$ by 10 to obtain the renal function testing intervals in months). ${ }^{34}$ In patients with additional risk factors (e.g., older age, frailty, multiple comorbidities), renal function may be evaluated even more frequently, especially if on dabigatran. Intercurrent acute illnesses like infections, acute heart failure, or contrast media exposure may rapidly affect the renal function and should also trigger prompt reevaluation; importantly, patients need to be alerted that they should seek contact with their health care provider in such situations. ${ }^{34}$

There are no randomized controlled trial (RCT) data on the use of DOACs for stroke prevention in AF patients with severe CKD or on renal replacement therapy, as all landmark DOAC trials essentially excluded patients with a $\mathrm{CrCl}$ of $<30 \mathrm{~mL} / \mathrm{min}$. However, VKAs have also never been prospectively assessed in RCTs in this patient population. ${ }^{34}$

A meta-analysis of RCTs compared VKA with DOACs ${ }^{50}$ in AF patients with normal, mild, or moderate renal function (except severe renal impairment: $\mathrm{CrCl}<30 \mathrm{~mL} / \mathrm{min}$ ). Five clinical trials were assessed, involving 72,608 patients. Pooled analysis indicated that the risk of stroke was lower for DOACs than for warfarin among patients with mild renal impairment (risk ratio: 0.79 ; $0.68-0.91)$ and moderate renal impairment $(0.80$; 0.69-0.92). Interestingly, no major differences were found in patients with normal renal function. Additionally, DOACs were associated with fewer major bleedings among patients with normal renal function $(0.77 ; 0.70-0.84)$, mild $(0.86$; 0.77-0.95), and moderate renal impairment (0.73; $0.65-0.82$ ), respectively. The authors conclude that DOACs provide a greater clinical benefit than warfarin in patients with impaired renal function. DOACs are associated with a comparatively lower risk of stroke and major bleeding, as well lower eGFR deterioration over time. This suggests that these agents are a better choice in renal disease.

A Danish registry study found that patients who had their DOAC dose reduced "only" due to age and frailty without a renal indication for dose reduction had a fivefold increased stroke rate with apixaban without significantly reducing bleeding risk compared with nonfrail patients (or patient under full therapeutic DOAC dose $)^{51}$; thus it is important to adhere to the Summary of Product Characteristics (SmPC) dose recommendations (see - Table 1 ).

For VTE treatment, the SmPC recommended dose in renal failure differs from that in AF treatment ( - Table 2); while in AF the doses of apixaban and rivaroxaban are reduced for a $\mathrm{CrCl}$ below 30 and $50 \mathrm{~mL} / \mathrm{min}$, respectively, there is no dose reduction in VTE treatment. This dosing difference between AF and VTE can be explained with the need for acute anticoagulant treatment in established acute VTE, versus prevention of blood formation in AF. Of course, when full-dose anticoagulation is used in renal insufficiency, this treatment should be performed with great caution. For rivaroxaban, a reduction of the maintenance dose from 20 to $15 \mathrm{mg}$ od (once daily) can be

Table 1 DOAC dose recommendations for patients with atrial fibrillation and renal insufficiency, based on German Summary of Product Characteristics (SmPC)

\begin{tabular}{|c|c|c|c|c|c|}
\hline \multicolumn{6}{|c|}{ Atrial fibrillation } \\
\hline \multirow[t]{2}{*}{ Trade name } & \multirow[t]{2}{*}{ Drug } & \multirow[t]{2}{*}{ Dialysis } & \multicolumn{2}{|c|}{ Creatinine clearance $(\mathrm{mL} / \mathrm{min})$} & \multirow[t]{2}{*}{$>50$} \\
\hline & & & $15-29$ & $30-50$ & \\
\hline \multirow[t]{2}{*}{ Pradaxa } & \multirow[t]{2}{*}{ Dabigatran } & \multirow[t]{5}{*}{ Not recommended } & \multirow[t]{2}{*}{ Contraindicated } & \multicolumn{2}{|c|}{$\begin{array}{l}150 \mathrm{mg} \text { bid }(\text { age } \geq 80 \text { y or } \\
\text { verapamil: } 110 \mathrm{mg} \text { bid) }\end{array}$} \\
\hline & & & & \multicolumn{2}{|c|}{$\begin{array}{l}\mathrm{CrCl} 30-50 \mathrm{~mL} / \mathrm{min} \text { or } \\
75-80 \mathrm{y} \text {, gastritis, elevated } \\
\text { bleeding risk: } 110 \mathrm{mg} \text { bid or } \\
150 \mathrm{mg} \text { bid depending on } \\
\text { thromboembolic and } \\
\text { bleeding risk }\end{array}$} \\
\hline Xarelto & Rivaroxaban & & $15 \mathrm{mg}$ od & $15 \mathrm{mg}$ od & $20 \mathrm{mg}$ od \\
\hline Eliquis & Apixaban & & $2.5 \mathrm{mg}$ bid & \multicolumn{2}{|c|}{$\begin{array}{l}5 \mathrm{mg} \text { bid } \\
2.5 \mathrm{mg} \text { bid if at least two of: } \\
\text { Age } \geq 80 \mathrm{y} \\
\leq 60 \mathrm{~kg} \\
\mathrm{~S} C \mathrm{Crea} \geq 1.5 \mathrm{mg} / \mathrm{dL} \\
(133 \mu \mathrm{mol} / \mathrm{L})\end{array}$} \\
\hline Lixiana & Edoxaban & & $30 \mathrm{mg}$ od & \multicolumn{2}{|l|}{$60 \mathrm{mg} \mathrm{od}^{\mathrm{a}}$} \\
\hline
\end{tabular}

Abbreviations: bid, twice a day; DOAC, direct oral anticoagulant; od, once daily.

${ }^{a}$ In patients with a body weight $<60 \mathrm{~kg}$ or concomitant use of the P-gp-Inhibitors Ciclosporine, Dronedarone, Erythromycine or Ketoconazole: 30 mg edoxaban od. 
Table 2 DOAC dose recommendations for patients with venous thromboembolism and renal insufficiency, based on German Summary of Product Characteristics (SmPC)

\begin{tabular}{|c|c|c|c|c|c|}
\hline \multicolumn{6}{|c|}{ Treatment of venous thromboembolism } \\
\hline \multirow[t]{2}{*}{ Trade name } & \multirow[t]{2}{*}{ Drug } & \multirow[t]{2}{*}{ Dialysis } & \multicolumn{2}{|c|}{$\begin{array}{l}\text { Creatinine clearance (- } \\
\mathrm{mL} / \mathrm{min})\end{array}$} & \multirow[t]{2}{*}{$>50$} \\
\hline & & & $15-29$ & $30-50$ & \\
\hline \multirow[t]{2}{*}{ Pradaxa } & \multirow[t]{2}{*}{ Dabigatran } & \multirow[t]{5}{*}{ Not recommended } & \multirow[t]{2}{*}{ Contraindicated } & \multicolumn{2}{|c|}{$150 \mathrm{mg}$ bid (age $\geq 80$ y or verapamil: $110 \mathrm{mg}$ bid) } \\
\hline & & & & \multicolumn{2}{|c|}{$\begin{array}{l}\mathrm{CrCl} 30-50 \mathrm{~mL} / \mathrm{min} \text { or } 75-80 \mathrm{y} \text {, gastritis, elevated } \\
\text { bleeding risk: } 110 \mathrm{mg} \text { bid or } 150 \mathrm{mg} \text { bid } \\
\text { depending on thromboembolic and bleeding risk }\end{array}$} \\
\hline Xarelto & Rivaroxaban & & \multicolumn{2}{|c|}{$\begin{array}{l}15 \mathrm{mg} \text { bid for } 3 \text { weeks, } \\
\text { then } 20 \mathrm{mg} \text { od or } 15 \mathrm{mg} \\
\text { od, if the estimated risk of } \\
\text { bleeding is higher than the } \\
\text { risk for thromboembolic } \\
\text { recurrence (with caution } \\
\text { for } 15-29 \mathrm{~mL} \mathrm{CrCl} \text { ) }\end{array}$} & $15 \mathrm{mg}$ bid for 3 weeks, then $20 \mathrm{mg}$ od \\
\hline Eliquis & Apixaban & & \multicolumn{3}{|c|}{$10 \mathrm{mg}$ bid for 1 week, then $5 \mathrm{mg}$ bid (with caution for $15-29 \mathrm{~mL} \mathrm{CrCl}$ ) } \\
\hline Lixiana & Edoxaban & & \multicolumn{2}{|l|}{$30 \mathrm{mg}$ od } & $60 \mathrm{mg} \mathrm{od}^{\mathrm{a}}$ \\
\hline
\end{tabular}

Abbreviations: bid, twice a day; DOAC, direct oral anticoagulant; od, once daily.

an patients with a body weight $<60 \mathrm{~kg}$ or concomitant use of the P-gp-Inhibitors Ciclosporine, Dronedarone, Erythromycine or Ketoconazole: 30 mg edoxaban od.

considered in patients with moderate renal impairment $(\mathrm{CrCl}$ : $30-49 \mathrm{~mL} / \mathrm{min})$, if the patient's assessed bleeding risk outweighs the risk of recurrent VTE ${ }^{12}$ (-Table 2). This is supported by observations from the RIETE registry ${ }^{39}$ : depending on the degree of renal insufficiency $(\mathrm{CrCl}>60,30-60$, and $<30 \mathrm{~mL} / \mathrm{min}$ ), the incidence of fatal pulmonary embolism within 15 days after diagnosis was $1.0,2.6$, and $6.6 \%$, respectively, which are significantly higher than the observed rates of fatal bleeding $(0.2,0.3$, and $1.2 \%$, respectively).

\section{Falls}

Several scales have been proposed for the definition of frailty and functional deficits in elderly persons, ${ }^{34}$ including factors that are associated with a high risk of falls. ${ }^{25,52}$ These include prior history of falls, lower extremity weakness, poor balance, cognitive impairment, orthostatic hypotension, use of psychotropic drugs, severe arthritis, and dizziness. A more formal tool is summarized in - Table 3, which had been developed and validated in 1,126 older community-living persons. ${ }^{53}$ In the general population above 65 years, there is a 1 to $2 \%$ risk of falls per year, and $5 \%$ of falls will result in fracture and hospitalization. ${ }^{54}$ The fear of falls and subsequent subdural hemorrhage are often reasons for not to initiate OAC or to discontinue OAC. A Markov decision analytic model has claimed that VKA patients would need to fall 295 times to outweigh the benefits of OACs by the risk of subdural hematoma. ${ }^{55}$ While this mathematical analysis has been cited numerously to support the use of OAC in elderly with risks of fall, the flaws of this analysis have not been addressed sufficiently: many of the important underlying assumptions for the Markov model were collected more than 40 years ago. Most importantly, the number of 295 falls required to outweigh the benefits of OAC refers to subdural hematoma, the rarest and not most severe complication in
Table 3 Risk score to assess the probability of falls per year ${ }^{53}$

\begin{tabular}{|c|c|c|c|c|}
\hline Previous falls & \multicolumn{4}{|c|}{ Yes/No } \\
\hline$>4$ medications & \multicolumn{4}{|c|}{ Yes/No } \\
\hline Psychotropics & \multicolumn{4}{|c|}{ Yes/No } \\
\hline Low visual acuity & \multicolumn{4}{|c|}{ Yes/No } \\
\hline Diminished sensation & \multicolumn{4}{|c|}{ Yes/No } \\
\hline Near tandem stand $10 \mathrm{~s}$ & \multicolumn{4}{|c|}{ Yes/No } \\
\hline Alternate step test $10 \mathrm{~s}$ & \multicolumn{4}{|c|}{ Yes/No } \\
\hline Sit to stand $<12 \mathrm{~s}$ & \multicolumn{4}{|c|}{ Yes/No } \\
\hline Score & $0-1$ & $2-3$ & $4-5$ & $6+$ \\
\hline Probability of fall per year & $7 \%$ & $13 \%$ & $27 \%$ & $49 \%$ \\
\hline
\end{tabular}

the Markov model, while other complications, like intracerebral hemorrhage (ICH) and-for example-non-CNS hemorrhages were 30 -fold more common. In patients above 90 years, mortality of falls is greatly increased (5.5 vs. $0.9 \%$ at $<60$ years), and the likelihood of home discharge is dramatically decreased (18.2 vs. $73.7 \%$, respectively). ${ }^{56}$ In this retrospective study of 5,088 patients with ground level falls, both aspirin use (1.42 [1.0-2.03]; $p=0.049)$ and anticoagulation with warfarin (OR: 2.24 [1.56-3.21]; $p<0.001$ ) were associated with increased overall mortality. ${ }^{56}$ Urgently, new data are required to either confirm or reject the 20 -year old calculations mentioned above ${ }^{55}$; until then, this reference should be cited with caution before drawing firm conclusions for patient management in 2020 and beyond.

Practically, patients who fall on OAC should be referred to a special service for multifactorial and multidisciplinary assessment of risk factors and to address remediable pathology and/or prescribe interventions (e.g., exercise programs; 
home environmental assessment a.s.o.) that reduce risk of further falls. ${ }^{57}$

Given the lower risk of subdural bleeding and ICH with DOACs compared with VKA, the "number needed to fall" would be beneficial with the use of DOACs. The effect of DOACs versus VKA in patients at risk of falling was analyzed specifically in two trials: prospectively in ENGAGE-AF TIMI $48^{58}$ with edoxaban, and retrospectively in the ARISTOTLE study with apixaban. ${ }^{59}$ The relative DOAC-treatment benefit in patients with an increased risk of falling was consistent with those without an increased risk. Because of the larger absolute risk of events in patients at risk for falls, DOACs are associated with a larger absolute risk reduction compared with VKA.

\section{Dementia and Anticoagulation}

Dementia is common in older age groups, and AF itself is a risk factor for dementia, and there is evidence that use of OAC may reduce the risk of dementia in AF by approximately onethird. $^{60}$

Dementia poses unique challenges for decision making, choice of treatment, and managing drug adherence. Importantly, dementia should not be a viewed as a general contraindication to OAC, especially if well managed (see below). Dementia patients should have a careful assessment of their ability to understand and make a treatment decision regarding OAC. Where capacity is deficient, it is rational for the physician to recommend treatment on the basis of the "best medical interest" principle, ideally including family members.

Adherence to OAC intake is very important in dementia. Once daily medications, weekly tablet boxes, reminders, and packing may be helpful. Paradoxically, the fact that others take care of providing medication may lead to a higher adherence.

\section{Polypharmacy}

With increasing age and with several underlying comorbidities, polypharmacy represents an additional challenge for OAC, particularly in AF. A posthoc analysis of the Aristotle study analyzed the association between polypharmacy ( $\geq 5$ drugs), comorbidities, and the occurrence of complications in patients receiving either apixaban or warfarin. ${ }^{61}$ Patients were divided into three groups, with either receiving 0 to 5,6 to 8 , or more than 9 concomitant drugs, respectively. Patients received a median of six drugs, and polypharmacy was seen in $76.5 \%$ of the 18,201 trial participants. More drugs were being used in elderly patients, women, and in the United States. The number of comorbidities increased with the number of drugs, including those that can interact with warfarin or apixaban. There was a significant increase of mortality as well as stroke/TE rate with the number of concomitant drugs ${ }^{61}$ ( - Fig. 2). However, the $\mathrm{RR}$ reduction of stroke/TE with the use of a DOAC remained consistent regardless of the number of concomitant drugs. This analysis shows the magnitude of the problem of OAC for stroke prevention: three quarters of the patients have five or more drugs, associated with increased comorbidities, more drug-drug interactions, higher mortality, and higher rates of thromboembolic or bleeding complications. Yet, use of DOACs was more effective and at least as safe as warfarin in these patients. ${ }^{61}$

For patients above 65 years, the appropriateness of anticoagulant drugs was reviewed based on the Fit-fOR-The-Aged (FORTA) classification. ${ }^{62-65}$ In a structured comprehensive

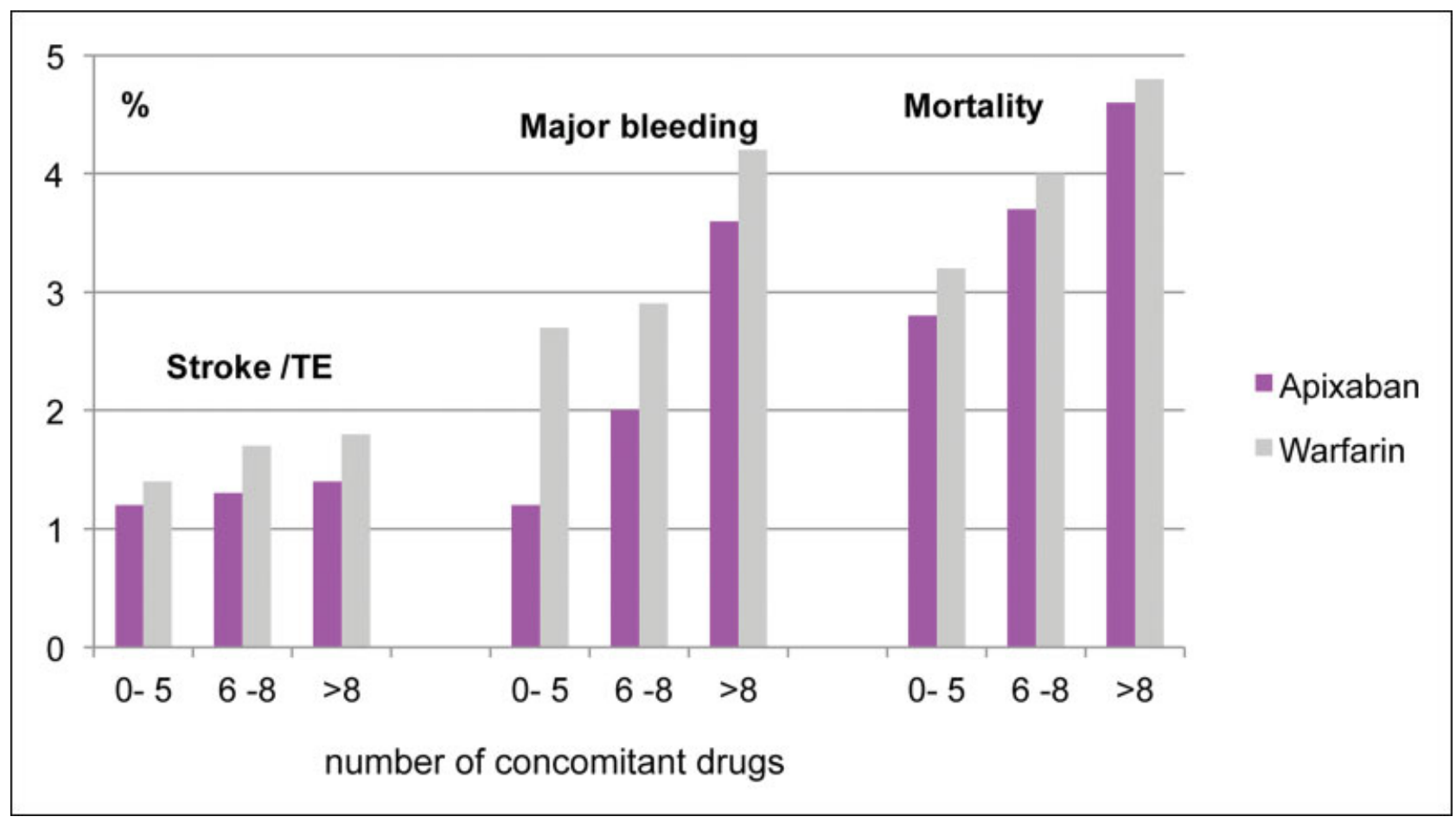

Fig. 2 Occurrence of stroke/TE, major bleeding and mortality, and number of concomitant drugs. Analysis of the ARISTOTLE-Study, which compared warfarin with apixaban in patients with atrial fibrillation. ${ }^{61} \mathrm{TE}$, thromboembolism. 
review of RCTs and summaries of individual SmPC, the resulting evidence was discussed. Decisions on age appropriateness were made using a Delphi process. Even though over 24,000 patients above 75 years were studied for warfarin, only two studies reported on frailty, falls, and dementia. Apixaban was classified as highly beneficial, and dabigatran, high-dose edoxaban, and warfarin were classified beneficial. Phenprocoumon, acenocoumarol, and fluindione were questionable, mainly because of lack of data. In conclusion, DOACs and warfarin were classified as beneficial or very beneficial in older patients.

Pharmacodynamic interactions are as important and should always be assessed. Coadministration of platelet inhibitors (including off-the-counter nonsteroidal anti-inflammatory drugs [NSAIDs] not listed in medication plan) increases the risk of bleeding, particularly in patients with underlying gastrointestinal lesions. In combination with NSAIDs or alone, selective serotonin reuptake inhibitors, in particular escitalopram, are associated with increased risk of major bleeding. ${ }^{66}$ Thus, these combinations should be carefully balanced against their potential benefit. The indication for coadministration of DOACs with dual-antiplatelet drugs requires active measures to reduce time on triple therapy, ${ }^{67}$ and administration of protonpump inhibitors should be considered. ${ }^{34}$

\section{Practical Considerations}

The above-mentioned specific aspects in elderly and frail patients illustrate that the decision on the type and dose of OAC is complex and is influenced by many clinical factors, which have to be considered both at the initiation of OAC and during regular follow-up visits. An example for a checklist to be thoroughly and regularly reviewed in elderly and frail patients is provided in - Table 4.

In patients with $\mathrm{AF}$, age also represents a risk factor for major bleeding, as indicated in the HAS-BLED Score. ${ }^{45}$ Importantly however, the HAS-BLED Score should not serve as a reason not to anticoagulate, as these patients commonly also have a very high risk for stroke; rather, attention should be paid to try to correct and minimize modifiable bleeding risk factors in these patients while on oral anticoagulation. ${ }^{7}$ Implantation of a left atrial appendage (LAA) occluder or surgical occlusion may be an option instead of long-term

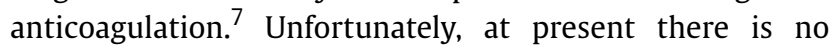

Table 4 Checklist of clinical parameters to be assessed at initiation of OAC and during regular follow-up visits

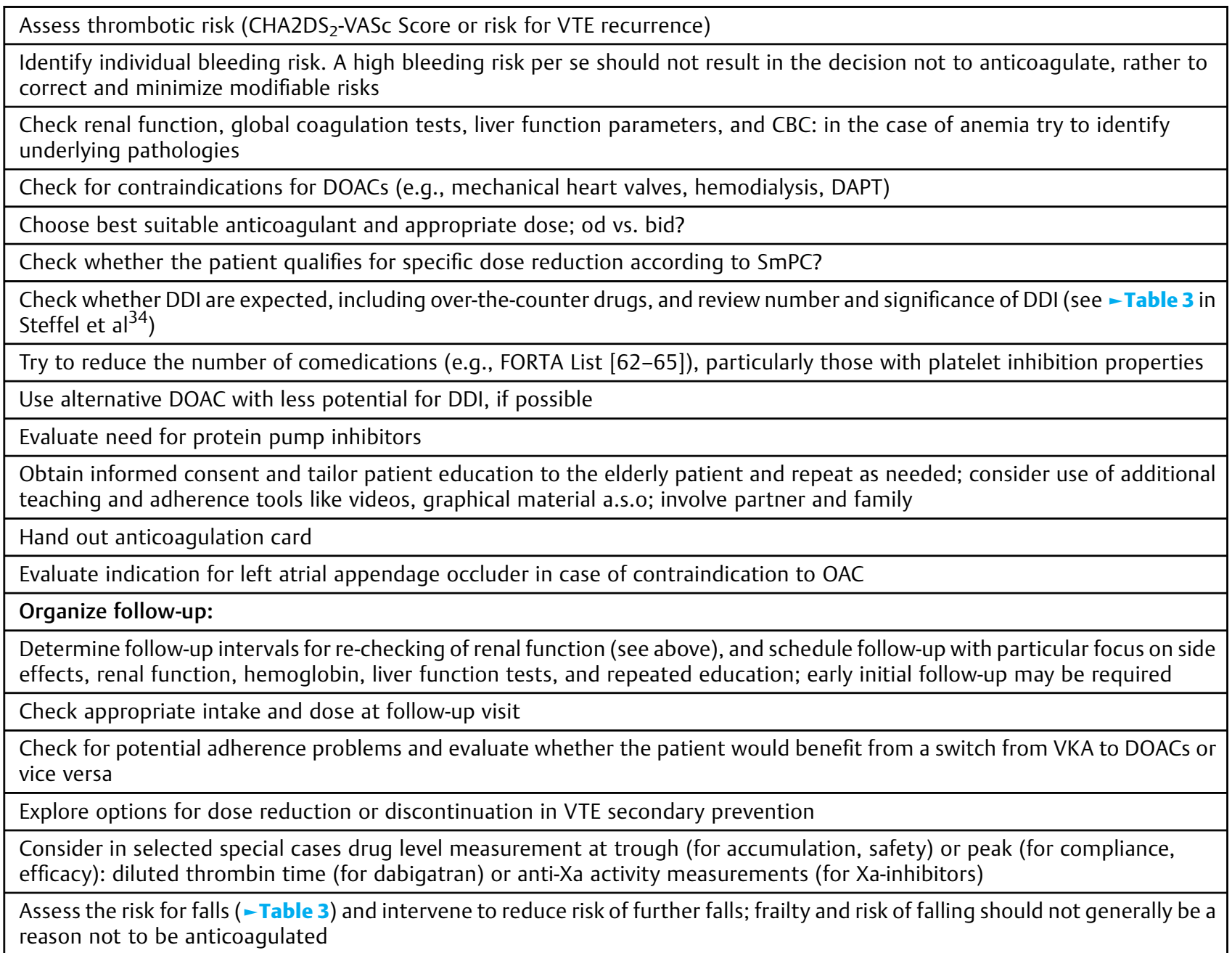


evidence from RCTs for LAA occlusion after OAC bleeding under OAC, e.g., compared with continued DOAC treatment in this challenging clinical situation. Additional important and valuable practical aspects for the treatment of AF with DOACs are summarized in the European Heart Rhythm Association Practical Guide. ${ }^{34}$

\section{Conclusions}

Elderly and frail patients requiring anticoagulation for AF or VTE are at a higher risk of adverse outcomes, but-at the same time-have a higher absolute benefit from OAC. Altered responses to drugs due to age-related physical decline, renal impairment, or low body weight have to be taken into account and may lead to suboptimal anticoagulation. Even though DOACs are superior to VKA because they exhibit predictable pharmacokinetics, eliminating the need for routine coagulation monitoring and dose adjustment, with fewer drug-drug interactions, extra attention and regular reviews are required to ensure safe and effective anticoagulation in elderly and frail patients.

\section{Conflicts of Interest}

J.H. has received honoraria for advisory boards, and/or travel support from LEO Pharma, Bayer, Bristol-Myers Squibb, and Pfizer.

R.M.B. has acted as a principal investigator in anticoagulation studies by Bayer, Bristol-Myers Squibb, Daiichi Sankyo, LEO, and Pfizer, and received honoraria for advisory boards or lectures from Bayer, Bristol-Myers Squibb, Daiichi Sankyo, LEO, and Pfizer.

\section{References}

1 Bevölkerung in absoluten Zahlen, Anteile der Altersgruppen in Prozent, 1960 bis 2050 Statistisches Bundesamt: Lange Reihen: Bevölkerung nach Altersgruppen, 13. koordinierte Bevölkerungsvorausberechnung: Bevölkerung Deutschlands bis 2060: Bundeszentrale für Politische Bildung; [Available from: Available at: https://www.bpb.de/nachschlagen/zahlen-und-fakten/soziale-situation-in-deutschland/61541/altersstruktur

2 Ergebnisse der 14. koordinierten Bevölkerungsvorausberechnung: Statistisches Bundesamt. Available at: https://www.destatis.de/DE/ Themen/Gesellschaft-Umwelt/Bevoelkerung/Bevoelkerungsvoraus berechnung/Tabellen/variante-1-2-3-altersgruppen.html;jsessionid $=452$ C6718CB5A674FB003FFF71486C2B9. internet712

3 Rosendaal FR, VAN Hylckama Vlieg A, Doggen CJ. Venous thrombosis in the elderly. J Thromb Haemost 2007;5(Suppl 1):310-317

4 Naess IA, Christiansen SC, Romundstad P, Cannegieter SC, Rosendaal FR, Hammerstrøm J. Incidence and mortality of venous thrombosis: a population-based study. J Thromb Haemost 2007;5 (04):692-699

5 van Es N, Coppens M, Schulman S, Middeldorp S, Büller HR. Direct oral anticoagulants compared with vitamin $\mathrm{K}$ antagonists for acute venous thromboembolism: evidence from phase 3 trials. Blood 2014;124(12):1968-1975

6 Go AS, Hylek EM, Phillips KA, et al. Prevalence of diagnosed atrial fibrillation in adults: national implications for rhythm management and stroke prevention: the AnTicoagulation and Risk Factors in Atrial Fibrillation (ATRIA) Study. JAMA 2001;285(18):2370-2375

7 Kirchhof P, Benussi S, Kotecha D, et al; ESC Scientific Document Group. 2016 ESC Guidelines for the management of atrial fibrilla- tion developed in collaboration with EACTS. Eur Heart J 2016;37 (38):2893-2962

8 Cruz-Jentoft AJ, Baeyens JP, Bauer JM, et al; European Working Group on Sarcopenia in Older People. Sarcopenia: European consensus on definition and diagnosis: report of the European Working Group on Sarcopenia in Older People. Age Ageing 2010; 39(04):412-423

9 Lacas A, Rockwood K. Frailty in primary care: a review of its conceptualization and implications for practice. BMC Med 2012; 10:4

10 Gobbens RJ, Luijkx KG, Wijnen-Sponselee MT, Schols JM. Towards an integral conceptual model of frailty. J Nutr Health Aging 2010; 14(03):175-181

11 Fried LP, Tangen CM, Walston J, et al; Cardiovascular Health Study Collaborative Research Group. Frailty in older adults: evidence for a phenotype. J Gerontol A Biol Sci Med Sci 2001; 56(03):M146-M156

12 Bauersachs RM. Managing venous thromboembolism with novel oral anticoagulants in the elderly and other high-risk patient groups. Eur J Intern Med 2014;25(07):600-606

13 Bauersachs RM. Use of anticoagulants in elderly patients. Thromb Res 2012;129(02):107-115

14 Prins MH, Lensing AW, Bauersachs R, et al; EINSTEIN Investigators. Oral rivaroxaban versus standard therapy for the treatment of symptomatic venous thromboembolism: a pooled analysis of the EINSTEIN-DVT and PE randomized studies. Thromb J 2013;11 (01):21

15 Oqab Z, Pournazari P, Sheldon RS. What is the impact of frailty on prescription of anticoagulation in elderly patients with atrial fibrillation? A systematic review and meta-analysis. J Atr Fibrillation 2018;10(06):1870

16 López-Jiménez L, Montero M, González-Fajardo JA, et al; RIETE Investigators. Venous thromboembolism in very elderly patients: findings from a prospective registry (RIETE). Haematologica 2006;91(08):1046-1051

17 Trujillo-Santos J, Schellong S, Falga C, et al; RIETE Investigators. Low-molecular-weight or unfractionated heparin in venous thromboembolism: the influence of renal function. Am J Med 2013;126(05):425.e1-434.e1

18 Mangoni AA, Jackson SH. Age-related changes in pharmacokinetics and pharmacodynamics: basic principles and practical applications. Br J Clin Pharmacol 2004;57(01):6-14

19 Garcia D, Regan S, Crowther M, Hughes RA, Hylek EM. Warfarin maintenance dosing patterns in clinical practice: implications for safer anticoagulation in the elderly population. Chest $2005 ; 127$ (06):2049-2056

20 Samama MM. Use of low-molecular-weight heparins and new anticoagulants in elderly patients with renal impairment. Drugs Aging 2011;28(03):177-193

21 Silverstein RL, Bauer KA, Cushman M, Esmon CT, Ershler WB, Tracy RP. Venous thrombosis in the elderly: more questions than answers. Blood 2007;110(09):3097-3101

22 Fohtung RB, Novak E, Rich MW. Effect of new oral anticoagulants on prescribing practices for atrial fibrillation in older adults. J Am Geriatr Soc 2017;65(11):2405-2412

23 Bai Y, Guo SD, Deng H, et al. Effectiveness and safety of oral anticoagulants in older patients with atrial fibrillation: a systematic review and meta-regression analysis. Age Ageing 2018;47 (01):9-17

24 Ruff CT, Giugliano RP, Braunwald E, et al. Comparison of the efficacy and safety of new oral anticoagulants with warfarin in patients with atrial fibrillation: a meta-analysis of randomised trials. Lancet 2014;383(9921):955-962

25 Kato ET, Giugliano RP, Ruff CT, et al. Efficacy and safety of edoxaban in elderly patients with atrial fibrillation in the ENGAGE AF-TIMI 48 trial. J Am Heart Assoc 2016;5(05):e003432

26 Patti G, Pecen L, Lucerna M, et al. Net clinical benefit of nonvitamin $\mathrm{K}$ antagonist vs vitamin $\mathrm{K}$ antagonist anticoagulants in 
elderly patients with atrial fibrillation. Am J Med 2019;132(06): 749.e5-757.e5

27 Bauersachs R, Berkowitz SD, Brenner B, et al; EINSTEIN Investigators. Oral rivaroxaban for symptomatic venous thromboembolism. N Engl J Med 2010;363(26):2499-2510

28 Bauersachs RM, Lensing AW, Prins MH, et al. Rivaroxaban versus enoxaparin/vitamin $\mathrm{K}$ antagonist therapy in patients with venous thromboembolism and renal impairment. Thromb J 2014;12:25

29 Sharma M, Cornelius VR, Patel JP, Davies JG, Molokhia M. Efficacy and harms of direct oral anticoagulants in the elderly for stroke prevention in atrial fibrillation and secondary prevention of venous thromboembolism: systematic review and meta-analysis. Circulation 2015;132(03):194-204

30 Büller HR, Décousus H, Grosso MA, et al; Hokusai-VTE Investigators. Edoxaban versus warfarin for the treatment of symptomatic venous thromboembolism. N Engl J Med 2013;369(15):1406-1415

31 Group IGOCW. KDIGO 2012 clinical practice guideline for the evaluation and management of chronic kidney disease. Kidney Int Suppl 2013;3:1-150

32 Erratum Regarding. Erratum regarding "KDOQI US commentary on the 2012 KDIGO clinical practice guideline for glomerulonephritis" (Am J Kidney Dis. 2013;62[3]:403-441). Am J Kidney Dis 2017;69(03):485

33 Sarnak MJ, Bloom R, Muntner P, et al. KDOQI US commentary on the 2013 KDIGO clinical practice guideline for lipid management in CKD. Am J Kidney Dis 2015;65(03):354-366

34 Steffel J, Verhamme P, Potpara TS, et al; ESC Scientific Document Group. The 2018 European Heart Rhythm Association Practical Guide on the use of non-vitamin K antagonist oral anticoagulants in patients with atrial fibrillation. Eur Heart J 2018;39(16):1330-1393

35 Soliman EZ, Prineas RJ, Go AS, et al; Chronic Renal Insufficiency Cohort (CRIC) Study Group. Chronic kidney disease and prevalent atrial fibrillation: the Chronic Renal Insufficiency Cohort (CRIC). Am Heart J 2010;159(06):1102-1107

36 Lee M, Saver JL, Chang KH, Liao HW, Chang SC, Ovbiagele B. Low glomerular filtration rate and risk of stroke: meta-analysis. BMJ 2010;341:c4249

37 Marinigh R, Lip GY, Fiotti N, Giansante C, Lane DA. Age as a risk factor for stroke in atrial fibrillation patients: implications for thromboprophylaxis. J Am Coll Cardiol 2010;56(11):827-837

38 Marinigh R, Lane DA, Lip GY. Severe renal impairment and stroke prevention in atrial fibrillation: implications for thromboprophylaxis and bleeding risk. J Am Coll Cardiol 2011;57(12):1339-1348

39 Monreal M, Falgá C, Valle R, et al; RIETE Investigators. Venous thromboembolism in patients with renal insufficiency: findings from the RIETE Registry. Am J Med 2006;119(12):1073-1079

40 Olesen JB, Lip GY, Kamper AL, et al. Stroke and bleeding in atrial fibrillation with chronic kidney disease. N Engl J Med 2012;367 (07):625-635

41 Lip GY, Frison L, Halperin JL, Lane DA. Comparative validation of a novel risk score for predicting bleeding risk in anticoagulated patients with atrial fibrillation: the HAS-BLED (hypertension, abnormal renal/liver function, stroke, bleeding history or predisposition, labile INR, elderly, drugs/alcohol concomitantly) score. J Am Coll Cardiol 2011;57(02):173-180

42 Gangireddy C, Rectenwald JR, Upchurch GR, et al. Risk factors and clinical impact of postoperative symptomatic venous thromboembolism. J Vasc Surg 2007;45(02):335-341, discussion 341-342

43 Engbers MJ, van Hylckama Vlieg A, Rosendaal FR. Venous thrombosis in the elderly: incidence, risk factors and risk groups. J Thromb Haemost 2010;8(10):2105-2112

44 Cook LM, Kahn SR, Goodwin J, Kovacs MJ. Frequency of renal impairment, advanced age, obesity and cancer in venous thromboembolism patients in clinical practice. J Thromb Haemost 2007; 5(05):937-941

45 Camm AJ, Kirchhof P, Lip GY, et al; European Heart Rhythm Association; European Association for Cardio-Thoracic Surgery. Guidelines for the management of atrial fibrillation: the Task
Force for the Management of Atrial Fibrillation of the European Society of Cardiology (ESC). Eur Heart J 2010;31(19):2369-2429

46 Gage BF, Yan Y, Milligan PE, et al. Clinical classification schemes for predicting hemorrhage: results from the National Registry of Atrial Fibrillation (NRAF). Am Heart J 2006;151(03):713-719

47 Dreisbach AW, Lertora JJ. The effect of chronic renal failure on drug metabolism and transport. Expert Opin Drug Metab Toxicol 2008;4(08):1065-1074

48 Limdi NA, Beasley TM, Baird MF, et al. Kidney function influences warfarin responsiveness and hemorrhagic complications. J Am Soc Nephrol 2009;20(04):912-921

49 Kleinow ME, Garwood CL, Clemente JL, Whittaker P. Effect of chronic kidney disease on warfarin management in a pharmacistmanaged anticoagulation clinic. J Manag Care Pharm 2011;17 (07):523-530

50 Zou R, Tao J, Shi W, et al. Meta-analysis of safety and efficacy for direct oral anticoagulation treatment of non-valvular atrial fibrillation in relation to renal function. Thromb Res 2017;160:41-50

51 Yao X, Shah ND, Sangaralingham LR, Gersh BJ, Noseworthy PA. Non-vitamin $\mathrm{K}$ antagonist oral anticoagulant dosing in patients with atrial fibrillation and renal dysfunction. J Am Coll Cardiol 2017;69(23):2779-2790

52 Donzé J, Clair C, Hug B, et al. Risk of falls and major bleeds in patients on oral anticoagulation therapy. Am J Med 2012;125(08): 773-778

53 Tiedemann A, Lord SR, Sherrington C. The development and validation of a brief performance-based fall risk assessment tool for use in primary care. J Gerontol A Biol Sci Med Sci 2010; 65(08):896-903

54 Rubenstein LZ. Falls in older people: epidemiology, risk factors and strategies for prevention. Age Ageing 2006;35(Suppl 2):ii37-ii41

55 Man-Son-Hing M, Nichol G, Lau A, Laupacis A. Choosing antithrombotic therapy for elderly patients with atrial fibrillation who are at risk for falls. Arch Intern Med 1999;159(07):677-685

56 Bhattacharya B, Maung A, Schuster K, Davis KA. The older they are the harder they fall: injury patterns and outcomes by age after ground level falls. Injury 2016;47(09):1955-1959

57 Tricco AC, Thomas SM, Veroniki AA, et al. Comparisons of interventions for preventing falls in older adults: a systematic review and meta-analysis. JAMA 2017;318(17):1687-1699

58 Steffel J, Giugliano RP, Braunwald E, et al. Edoxaban versus warfarin in atrial fibrillation patients at risk of falling: ENGAGE AF-TIMI 48 analysis. J Am Coll Cardiol 2016;68(11):1169-1178

59 Rao MP, Vinereanu D, Wojdyla DM, et al; Apixaban for Reduction in Stroke Other Thromboembolic Events in Atrial Fibrillation (ARISTOTLE) Investigators. Clinical outcomes and history of fall in patients with atrial fibrillation treated with oral anticoagulation: insights from the ARISTOTLE trial. Am J Med 2018;131(03): 269-275.e2

60 Friberg L, Andersson T, Rosenqvist M. Less dementia and stroke in low-risk patients with atrial fibrillation taking oral anticoagulation. Eur Heart J 2019;40(28):2327-2335

61 Jaspers Focks J, Brouwer MA, Wojdyla DM, et al. Polypharmacy and effects of apixaban versus warfarin in patients with atrial fibrillation: post hoc analysis of the ARISTOTLE trial. BMJ 2016; 353:i2868

62 Wehling M, Collins R, Gil VM, et al. Appropriateness of oral anticoagulants for the long-term treatment of atrial fibrillation in older people: results of an evidence-based review and international consensus validation process (OAC-FORTA 2016). Drugs Aging 2017;34(07):499-507

63 Pazan F, Weiss C, Wehling M; FORTA. The FORTA (Fit fOR The Aged) list 2015: update of a validated clinical tool for improved pharmacotherapy in the elderly. Drugs Aging 2016;33(06):447-449

64 Pazan F, Weiss C, Wehling M; FORTA. Correction to: the EUROFORTA (Fit fOR The Aged) list: international consensus validation of a clinical tool for improved drug treatment in older people. Drugs Aging 2018;35(07):677 
65 Pazan F, Weiss C, Wehling M; FORTA. The EURO-FORTA (Fit fOR The Aged) list: international consensus validation of a clinical tool for improved drug treatment in older people. Drugs Aging 2018; 35(01):61-71

66 Samuel NG, Seifert CF. Risk of bleeding in patients on full-dose enoxaparin with venous thromboembolism and selective serotonin reuptake inhibitors. Ann Pharmacother 2017;51(03):226-231
67 Roffi M, Patrono C, Collet JP, et al; ESC Scientific Document Group. 2015 ESC guidelines for the management of acute coronary syndromes in patients presenting without persistent ST-segment elevation: task force for the management of acute coronary syndromes in patients presenting without persistent ST-segment elevation of the European Society of Cardiology (ESC). Eur Heart J 2016;37(03):267-315 